\title{
Operation of an employee suggestion system in administration and production departments of a remanufacturing company
}

\author{
Damian Ostrowski ${ }^{1}$. Jacek Jagodziński ${ }^{2}$ i
}

Received: 11 February 2020 / Accepted: 11 September 2020 / Published online: 20 October 2020

(C) The Author(s) 2020

\begin{abstract}
Purpose The aim of the article is to discuss the issues of the employee suggestion system (ESS) in a remanufacturing enterprise. ESS is a tool used in many modern management philosophies like continuous improvement, Kaizen, lean etc. A number of factors influencing the operation of the employee suggestion system (ESS) were examined in the literature. However, none considers the fact that within various departments, the nature of this tool may vary.
\end{abstract}

Methodology/approach Based on the data from a representative international company, the system performance was assessed. Using statistical tests, it was examined whether the ESS works identically in different departments of the company. The article reviews the literature and attempts to explain the reasons for the results.

Findings On the basis of statistical tests, it has been proved that despite the same implementation and occurrence of the same types of waste in various departments, the number of employee suggestions and thus the functioning of the system is different. According to the authors, the reason for this is the fact that the company performs remanufacturing processes. Managing an enterprise using lean remanufacturing has a specific character in relation to classic lean.

Recommendations Since the article presents only one example of a company in which this phenomenon appeared and the lack of this issue in the literature, further analysis of this problem is necessary.

Keywords Employee Suggestion System (ESS) - Lean management · Lean remanufacturing · Transport company $\cdot$ Kaizen · Production · Waste

Damian Ostrowski

damian.ostrowski@wsb.wroclaw.pl

Jacek Jagodziński

jacek.jagodzinski@pwr.edu.pl

1 WSB University in Wrocław, Fabryczna 29-31, 53-609, Wrocław, Poland

2 Department of Control Systems and Mechatronics, Wrocław University of Science and Technology, Janiszewskiego 11-17, 50-372, Wrocław, Poland 


\section{Introduction}

The research under consideration concerns an operation analysis of one of the tools most often applied in modern management methods, namely employee suggestion systems. Proposals of improvements of various processes made by employees of the lowest levels people who actively complete a task are very valuable and constitute the basis for numerous corporate organization methods such as continuous improvement, Kaizen and others.

The article concerns the employee suggestion system (ESS) in the area of lean remanufacturing. The literature in this area was reviewed (August 2020). In the Web Of Science database, 1101 papers were found with the phrase "employee suggestion system" and 32 papers about "lean remanufacturing". Various combinations of phrases did not produce any results (for example "suggestion system" and "lean remanufacturing" - 0, "suggestion system" and "remanufacturing" - 1 but in different topic). Similarly, the Scopus database did not produce any relevant results ("employee suggestion system" - 770, "lean remanufacturing" - 1447, "suggestion system" and "lean remanufacturing" - 0, "suggestion system" and "remanufacturing" - 0). Additionally, a review of Google Scholar databases, in the case of combinations of the words "suggestion system", "lean remanufacturing" returned - 2 articles, while "suggestion system", regeneration - 50 papers. However, most often they belong to research related to sustainable development. It is worth noting that the ESS is also part of the trend related to sustainable development. The assumptions of sustainable development are particularly relevant at present [5].

The literature provides a series of factors affecting the success of an employee suggestion system. Based on a broad literature review, Lasardo et al. [24] indicate 32 factors affecting success of the system. There are also a lot of commonly and formally accepted procedures managing employee suggestions. Analyses of these processes are also subject to scientific research [33], [9], [23]. Systemized approach towards employee suggestions, a modern and traditional reflection were presented by Pakdel et al. [27]. Proposals of measuring maturity of an employee suggestion system were presented in the paper [25] whereas an example of effectiveness evaluation of the method can be found in works of Arif et al. [3]. In their work Gołaś et al. have shown how an employee suggestion system influences effectiveness of an enterprise. It was measured by the number of implemented employee suggestions in various areas of operation. The greatest impact referred to the quality i.e. $27 \%$, safety/ergonomics $23 \%$ and cleanliness $18 \%$ [11].

In view of the scientific elaborations presented as regards operation and evaluation of employee suggestion systems, attention is not paid to the fact that both effectiveness as well as procedures may differ depending on a company department. For instance, production and administration departments are naturally different. Administration departments are in charge of management activities, coordination of processes and finally of winning customers through appropriate marketing. Very often it is difficult to define the quality of introduced changes. Whereas production (services) focuses on manufacturing certain goods, most often they are physical goods which may be assessed explicitly on the basis of quality checks. Despite the fact that an employee suggestion system is universal and may be applied in any industry, it will possess specific features on the level of two different applications. In more general terms, one must consider how an employee suggestion system affects various philosophies such as Kaizen or TQM which make use of this tool. Does continuous improvement work well in both administration and production departments? In foreign literature one may find numerous elaborations which state that "Kaizen works equally well in office (administrative procedures) and shop (production processes) settings." [4], though 
this statement is limited to small and medium enterprises, there are also broader elaborations. On Kaizen websites (www.kaizen-news.com) Wilson presents cases also confirming the hypothesis regarding compliance of effectiveness in the two areas [33]. Also Göransson and Tunovic are convinced about this compliance although they display different ways of implementation [12].

The paper will present results of implementing an employee suggestion system in administration and production departments of a selected Polish enterprise. An attempt was made to compare differences between employee suggestion systems of the two departments based on statistic tests.

\section{An employee suggestion system - a theoretical approach}

An interesting, in-depth review of the world literature on lean management (theory, tools, trend) is presented in the article by Yadav et al. [34]. One of the basic claims related to effective implementation of lean philosophy is the conviction that lean is not only a set of tools and techniques of direct application but also an action philosophy and a system consisting of the basic element such as people [16]. The work environment based on lean management principles is built on different values and conviction varying from other work systems. In the lean approach:

- an employee should be aware of dynamic changes and complete openness and involvement into quick reaction,

- $\quad$ work is based on strict compliance with principles, rules and standards,

- an employee should accept a multidimensional nature of their work and multitasking,

- an ability to work in a team,

- solving problems all the time and improving their work place [16].

Due to its universal principles, the lean management philosophy is readily used in other areas. It is now believed that the lean management concept should be considered in conjunction with other approaches, eg agile, green, resilient, etc. The differences and similarities discussed can be found in the article by Carvalho et al. [6]. The literature indicates that Amezquita was one of the pioneers in the connection between lean and remanufacturing. [2] demonstrated the benefits of using the lean approach in improving the efficiency of remanufacturing processes. A similar opinion is expressed by Fagrher, who identified the benefits of using lean in remanufacturing processes by eliminating activities that do not bring added value [10]. Pawlik argues that combining lean management with remanufacturing creates opportunities to increase efficiency in the remanufacturing industry [28]. John Dally defines lean in remanufacturing processes as a fundamental way to improve the factories operations by focusing on product flow, speed of operations and elimination of waste [8]. Kurilova-Palisaitiene points out that lean remanufacturing is useful for optimizing process lead times [19]. However, some researchers show challenges in implementing lean manufacturing in remanufacturing processes. In their work, Kanikula and Koch present the following problems [17]:

- "not every remanufacturing operation is needed in each remanufacturing process,

- difficulties in definition of takt time for remanufacturing systems (not always consumer demand is known)

- cycle times varies and it depends on quality or repeatability of incoming products, 
- quantity of disassembled parts varies and it also depends on quality or repeatabil- ity of incoming products,

- diversity in range of products,

- possible huge amount of core (used products) inventory waiting for disassembly,

- sometimes no high-runners."

In their article, Kurilova-Palisaitiene and Sundin claim, citing examples, that it is very difficult even impossible to implement a lean approach to remanufacturing due to the greater complexity of processes, the unique cycles and operations, quantity and quality requirements, and other stock levels [18]. The authors of this study assume, however, that the implementation of lean manufacturing into remanufacturing processes is possible under certain strict conditions. It requires appropriate adaptation to the remanufacture nature, adjusting the implementation of selected lean tools each time, in accordance with the company's profile. There are studies in the literature on lean remanufacturing that raise the issue of appropriate adaptation of lean assumptions and values to manufacturing processes, however, there is a gap in the studies on specific lean tools in remanufacturing [29]. In this study, the authors try to fill this gap and undertake an analysis of the application in theory and practice of the tool employee suggestion system in an organization that is both manufacturing and remanufacturing. In the process of implementing the principles of the employee suggestion system, there are no significant differences regarding enterprises operating under lean manufacturing or lean remanufacturing.

The literature on lean subject often emphasizes that a successful transformation of an enterprise towards the lean concept should be related to appropriate motivation of employees to work. It is commonly believed that a financial incentive is the main factor affecting engagement of employees. Nevertheless, on the basis of works of an American psychologist F. Herzberg we may definitely state that "money does not motivate people to engage more, it does not generate willingness to make a voluntary effort to improve processes they are working at. In order to achieve it, more is needed to make work and its conditions comply with internal development needs, ambitions and satisfaction of employees" [16]. Therefore, it is proposed to base implementation of lean philosophy on natural motivators generating desired attitudes of employees such as:

- $\quad$ making sense of work of an individual,

- $\quad$ arousing a feeling of fulfilment at work,

- involvement,

- removing waste from tasks to be completed,

- solving problems in a team,

- recognizing one's effort,

- passing ownership of a process or an area [16].

The lean concept instruments which correspond to the above proposals to strengthen employee motivation emphasize the importance of various programs, systems encouraging employees to share their ideas, suggestions regarding improvements and modifications to processes, work positions, standards etc. The management literature introduced the first documented system of notifying ideas improving operation of an organization in 1770 in the British Navy. In 19th century some enterprises in USA and Great Britain used the so called boxes for ideas. Toyota introduced this system in 1951 inspired by Motor Company [22]. The creator of Toyota Production System - Taiichi Ohno asked aboyt the success of implementing Kaizen rules said "If it is only possible ask people doing a job for opinions. 
Wisdom originates from ideas of novices" citeShimokawa. It is essential to emphasise the role of employees performing basic activities, they can improve an organization in a simple way using cost-effective solutions. A colourful description of this dependency is found in a book written by Koichi Shimokawa, Takahiro Fujimoto, The Birth of a Management System, the conversation with Taiichu Ohno and Eiji Toyody: "My uncle is 93 years old and has a hearing problem. The laryngologist told him he needed a hearing aid and that it was normal for his age. My uncle bought an expensive hearing aid. A few days later he went to a barber. He told him that his hearing had got worse so he bought a hearing aid. Have you cleaned your ears recently?, the barber asked. Not really, my uncle responded. Let us have a look. Then the barber took a lot of earwax out of his ears. Suddenly, my uncle began to hear well without a hearing aid" [32]. Toyota is a model organization as regards implementation of lean management, an employee suggestion system in Toyota is called TSP (Toyota Suggestion Program), it is based on the assumption that employees themselves aspire to improve their working environment, thanks to which each employee contributes to a longterm improvement in company operation. The system is also perceived as a programme affecting financial standing of a company as well as a full identification of employees with an enterprise. As its authors emphasize it is not only about savings but first of all an increase in job satisfaction. The programme creates an appropriate atmosphere and a feeling that everyone contributes to an overall success of a company by providing ideas. The system is profitable as it achieves an investment return rate on the level from seven to one. Employees are assumed to come up with about 10 suggestions per annum. [20]. In Toyota Motor Poland dozens of ideas are developed every year which are implemented in big factories in the world and Poland employing several thousands of workers even 5 - 6 thousand [30]. An example of an idea implemented in all Toyota companies was developed in Wałbrzych and was based on the following observation "a production worker pouring a cooling liquid into a machine noticed that its amount reduced by half also cools the machine down. When his observation was researched by a team of analysts, it turned out to be true. His idea generated huge savings" [30]. An employee suggestion system plays a crucial role in counteracting the eighth type of waste such as unused employee creativity defined as "the result of no involvement of employees into tasks who have right competences, inability to listen to employees, not paying attention to their employees, making it impossible for employees to learn at the same time" [21]. The operation of an employee suggestion system is based on the following assumptions:

- implementation of all suggestions made even those providing little value added to an entity as compared to expenditure (labour, costs) incurred for its implementation.

- operation of a process of evaluating and giving an opinion about a suggestion before its implementation (yes or no system, acceptance is dependent on the existence of the value added).

- Functioning of a separate organization unit in charge of promoting Kaizen culture, communication with employees and evaluation of motions.

- in-depth process standardization so that an implemented suggestion was binding throughout its entire economic usefulness instead disappearing as the staff rotates. This is a key element without which a suggestion system will not be effective in the long-term.

- implementation of a suggestion by its author or supervised by its author.

- Securing employees with necessary knowledge and tools for effective elaboration of their own improvement projects through periodic training [13]. 
When describing the differences in the functioning of the ESS in developed and developing countries, it is necessary to emphasize the differences in the social, technological and economic context that affect the development of the ESS.

- low human capital providing the labor force to have poor skills, which leads to poor labor productivity. While for developed countries typical are high levels of human capital, providing the labor force to be significantly educated and skilled. This makes it easier to engrain new technology continuously, causing high labor productivity,

- an educational sector, presented by educational institutions, labor training institutions and others, which are not in a sufficient amount for underdeveloped countries. That is why people there do not have an opportunity to learn the modern economic techniques of goods and services production and distribution,

- technology, researched and developed In most underdeveloped countries there can be some researches and practices committed at a low level, but nothing more. However, the developed countries technology sector is shown to be significantly emphasized and invested in for a prosperous future. [1]

Some researchers argue that "The transferability of Kaizen-oriented suggestion systems (KOSS) to organizations outside Japan is discussed. It is concluded that, although national culture is to some extent the reason for Kaizen's success in Japan, a successful transfer of KOSS is less dependent on an amenable national culture than on the organizational culture" [31]. In the article Jabeen et al. [14] characterized the factors influencing the development of ESS in GCC - developing countries (Saudi Arabia, Qatar, Oman, United Arab Emirates). The research indicate that leaders management support, individual traits and organization culture are the key drivers that influence employees involvement in an ESS. The authors [7] expressed a negative opinion about the functioning of ESS in one of the South African companies, who stated, that majority of the respondents opined a lack of systematic mechanism for the practice and administration of the Kaizen suggestion tools in most Eastern Cape automotive companies.

Summarizing the difference between the functioning of the ESS in developed and developing countries, it should be stated that the formal principles of ESS systems operation are similar, however, social factors such as the level of education, the level of trust between employees and the employer, religion, openness, organizational culture, motivations that differ in practice. An important element is the development lean management (including ESS) in developing countries, because as it Yadav et al. [35] claims, the introduction of lean management in developed countries has contributed to an increase in product quality, productivity, working conditions and customer satisfaction. Yadav et al. emphasizes that the implementation of lean management in developing countries is marginal.

\section{The enterprise surveyed}

The enterprise under consideration is the biggest international investor in the transport industry. It employs over 1500 people in Poland. It has got 4 production facilities in Poland - in Silesian region, Łódź, Masovian and Lower Silesian regions. The facility in Lower Silesia has continued the tradition of manufacturing vehicles: bodies and bogie frames since 1833. After 1945 the company was one of the biggest in Poland it terms of the production volume and the number of employees. Since 2001 the company has belonged to an international concern based in the North America. Transport companies from Germany, Sweden, 


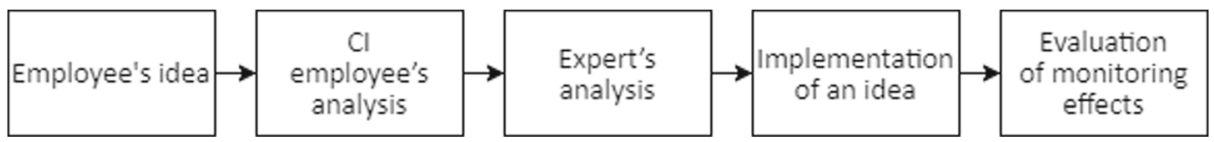

Fig. 1 The process of an employee suggestion system operation in an enterprise.

Switzerland, USA and Italy use its products. The enterprise employs 700 employees: 200 in administration and 500 in production (company website). The company began to implement an employee suggestion system in 2006.

A characteristic feature of the enterprise is its diversified core activity. Due to the fact that it is a global organization, it is focused on implementing new product projects, especially for foreign clients from Western Europe and North America. However, considering the location in Poland (Eastern Europe), the company offers remanufacturing services for clients from Eastern European countries and former Soviet republics, which are particularly interested in the reproduction processes of old, outdated products. Due to its specificity, the described company is affected by seasonal factors. In some periods, the number of manufacturing processes exceeds remanufacturing and sometimes it's the opposite.

\section{The process of reporting and evaluating employee ideas in enterprise $X$}

A continuous improvement department (CI) is in charge of effective operation of an employee suggestion system. ${ }^{1}$ The department has got a computer system - a database (accessible by all employees) registering, describing and archiving all employee suggestions. ${ }^{2}$ Registration of a suggestion is done the moment an employee receives a form from the department, most often the contact is made through 5 boxes in the company where employees can put appropriate forms for reporting a suggestion prepared by CI employees. The boxes are checked on the on-going basis. The other way of contacting, a less practical one, is to deliver a form with a suggestion directly to the department or hand it over to a CI department employee who you meet in the workshop floor. CI employees analyse "Kaizen" they have received in terms of correctness and justifiability and if they think an idea meets formal requirements, they transfer it to the right consultant (an advisor, an expert) (an expert has 5 days to deliver an opinion to the CI department) who evaluates thoroughly the idea taking into account quantitative, cost and organizational criteria. A key element of the process is a decision of the so called owner of a budget who decides about justifiability of a specific idea considering a cost criterion. Time of implementation, its effects are analysed and possibly a decision is made about withdrawing an idea depending on circumstances which were not identified during the analysing stage.

Then, once a quarter all reported (implemented) ideas are evaluated in terms of various criteria (e.g. the quality, costs, organization, work safety etc.) and employees are rewarded - this is an element of a broader strategy of motivating employees. A simplified operation of an employee suggestion system is presented in Fig. 1.

Rules of an Employee Incentive Programme "Kaizen - continuous improvement" including an attachment of enterprise $\mathrm{X}$ govern the operation of an employee suggestion system.

\footnotetext{
${ }^{1}$ In the surveyed enterprise an idea, a suggestion made by an employee is commonly called "Kaizen". That is why the author are going to refer to this name in this elaboration.

${ }^{2}$ The databases register all notifications regardless of their status e.g. reported, implemented, rejected etc.
} 
This document includes definitions of terms regarding the employee suggestion programme, the role of continuous improvement in organization of an employee suggestion process, defined principles of giving awards, principles of calculating points for employee suggestions etc. The attachment to the rules is its integral part containing a visualized process of reporting, registering and implementing kaizen motions. The ideas which have generated noticeable benefits for the company and are possible to adopt in other production facilities are diffused meaning they are transferred to other factories in the group located worldwide. This way undisclosed knowledge of employees is transformed into disclosed knowledge which is structured, archived and may be used by the organization in order to build a knowledge-based company. Functioning of such a system favours building more permanent relations between an employer and employees. The data that was analysed had been obtained from enterprise $\mathrm{X}$ during an internship under Mozart programme funded by the Municipality of Wrocław.

\section{Researching employee suggestions in enterprise $X$}

The research carried out in the enterprise concerns the employee suggestion system so the reasoning refers to this aspect. Nevertheless, it is worthwhile looking at the way of thinking presented in the work [33]: based on a case study the author indicates compatibility between Kazien and continuous improvement. As continuous improvement may be evaluated on the basis of the number of improvements- the number of employee suggestionsthis leads to concluding about the mere methodology of Kaizen. To sum up, a tool used in a certain method is researched so making conclusions on the basis of the research carried out is a starting point for concluding about a certain scope of the philosophy making use of the tool. The employee suggestion system in the researched enterprise is one of the elements of implemented Kaizen philosophy so evaluation constitutes an important aspect of approaching continuous improvements.

It should be emphasized that implementation of some employee ideas takes even two or three years so the analysis of years 2016 - 2017 would not contribute significantly to the research. The research was made into possible dependence between the number of implemented and non-implemented employee suggestions in administration and production departments. This action on one hand evaluates resilience, willingness to act and report new ideas by a department, on the other hand it evaluates the quality of pioneer solutions. The implemented solutions are well-though, realistic to implement and profitable for a company. Mutual dependency between ideas which were realized and those rejected constitutes measurement of the quality of presented solutions.

The hypothesis has formally been formulated as follows: there is no significant dependency between company departments and the number of implemented employee suggestions within a specific year. The statistical hypothesis test $\chi^{2}$ was used to answer this question. The matrix for calculations comprised 2 (departments) per 2 (implemented/nonimplemented) so a degree of freedom amounts $1(d . f .=1)$. Therefore, the Yates correction was applied. The research results for particular years are presented in Table 2.

The research making use of the test $\chi^{2}$ most often assumes the level of materiality equal to $5 \%$ - such a level was arbitrarily chosen in this elaboration. Based on the collected data and on the confidence level lower than $0.2 \%$ it was shown that there is a dependency between a department and the number of implemented and non-implemented employee suggestions - for the total of employee suggestions (c.f. data marked with total in Tables 1 
Table 1 The number of implemented and not implemented employee suggestions according to departments of enterprise $\mathrm{X}$ broken down into years

\begin{tabular}{|c|c|c|c|c|c|c|}
\hline \multicolumn{7}{|l|}{ Implemented } \\
\hline Departments/years & 2006 & 2007 & 2008 & 2009 & 2010 & \\
\hline Administration & 6 & 121 & 218 & 237 & 285 & \\
\hline Production & 21 & 101 & 282 & 450 & 146 & \\
\hline Departments/years & 2011 & 2012 & 2013 & 2014 & 2015 & Total \\
\hline Administration & 499 & 89 & 43 & 97 & 113 & 1708 \\
\hline Production & 153 & 197 & 258 & 182 & 396 & 2186 \\
\hline \multicolumn{7}{|l|}{ Not implemented } \\
\hline Departments/years & 2006 & 2007 & 2008 & 2009 & 2010 & \\
\hline Administration & 3 & 26 & 183 & 218 & 127 & \\
\hline Production & 4 & 83 & 107 & 228 & 94 & \\
\hline Departments/years & 2011 & 2012 & 2013 & 2014 & 2015 & Total \\
\hline Administration & 190 & 53 & 37 & 44 & 95 & 976 \\
\hline Production & 143 & 69 & 52 & 64 & 207 & 1051 \\
\hline
\end{tabular}

and 2). The research results for particular years (Table 2) apart from the test results also contain values, V Cramer's coefficient. The analysis of Table 2 proves that on the assumed level of 5\% independence is observed only in year 2006, 2010 and 2014 - there is no formal basis for rejecting the zero hypothesis. Due to the beginning of implementation of the employee suggestion procedure (small number) year 2006 should be perceived as a preliminary trend to act for the system, non-necessarily a general trend. However, over the remaining years (excluding 2010, 2014) we can observe a significant dependency. Therefore, on the basis of the statistical test we may say that the employee suggestions systems in the administration and production systems differ significantly.

To make results more precise Table 3 presents a percentage deviation for the years showing the dependency $(2010,2014)$ as well as a comparison of all years. It indicates that the actual company data differs from the excepted data.

As regards 2010 the maximum percentage deviation is on the level of $14.9 \%$ (for the nonimplemented production) whereas in 2014 it amounts to $10.5 \%$ (for the non-implemented

Table 2 Statistical tests

\begin{tabular}{|c|c|c|c|c|c|c|}
\hline & 2006 & 2007 & 2008 & 2009 & 2010 & \\
\hline$\chi^{2}$ Yates & 0.39 & 28.32 & 27.16 & 22,68 & 4,34 & \\
\hline p-value & 0.5323 & $10^{-4}$ & $10^{-4}$ & $10^{-4}$ & 0.0372 & \\
\hline \multirow[t]{2}{*}{ Cra-mer's V } & 0.1894 & 0.2976 & 0.188 & 0.1433 & 0.085 & \\
\hline & 2011 & 2012 & 2013 & 2014 & 2015 & Total \\
\hline$\chi^{2}$ Yates & 38.86 & 5.19 & 29.72 & 0.96 & 8.04 & 9.72 \\
\hline $\mathrm{p}$-value & $10^{-4}$ & 0.0227 & $10^{-4}$ & 0.3272 & 0.0046 & 0.0018 \\
\hline Cra-mer's V & 0.201 & 0.1184 & 0.2836 & 0.0557 & 0.1025 & 0.0409 \\
\hline
\end{tabular}


Table 3 Percentage deviation for all accumulated years (a total) and years 2010 and 2014

\begin{tabular}{lllllll}
\hline Years & Total $(2006-2015)$ & 2010 & & \multicolumn{2}{c}{2014} \\
\hline & imp. & Not-imp. & imp. & Not-imp. & imp. & Not-imp. \\
Administration & $-3,2 \%$ & $+6,2 \%$ & $+4,5 \%$ & $-8,7 \%$ & $-4,1 \%$ & $+10,5 \%$ \\
Production & $+2,7 \%$ & $-5,1 \%$ & $-7,7 \%$ & $+14,9 \%$ & $+2,3 \%$ & $-6 \%$ \\
\hline
\end{tabular}

administration). In fact, it means how much the number of employee suggestions in a particular specification exceeds their expected number. Deviations from the expected value are not big, it is worthwhile comparing them to all years where a negative result of the test is on the level of 1.8 per mille when the maximum percentage deviation amounts to $6.2 \%$.

Additionally, the research was made into the fact whether there is a relation between departments and subsequent years for the number of implemented employee suggestions. The result of test $\chi^{2}$, with a degree of freedom at 9 amounted to 641.394 which gives a pvalue below $10^{-9}$ so we can speak about dependence between the administration and the production in creating implemented solutions. The data from the table was visualized in Fig. 2.

To sum up, there is a significant difference between implemented and non-implemented employee suggestions (in total and in particular years) as regards the administration and the production. Attention should be drawn to a certain dynamics, according to the presented data in the first years the administration prevails in terms of the number of implementations whereas since 2012 the administration reveals less activity as compared to the previous years (c.f. 2). A conclusion may be reached that employee ideas in the administration department have a different nature as compared to those from the production. In a management department certain management manners may be easily changed so the process of working out

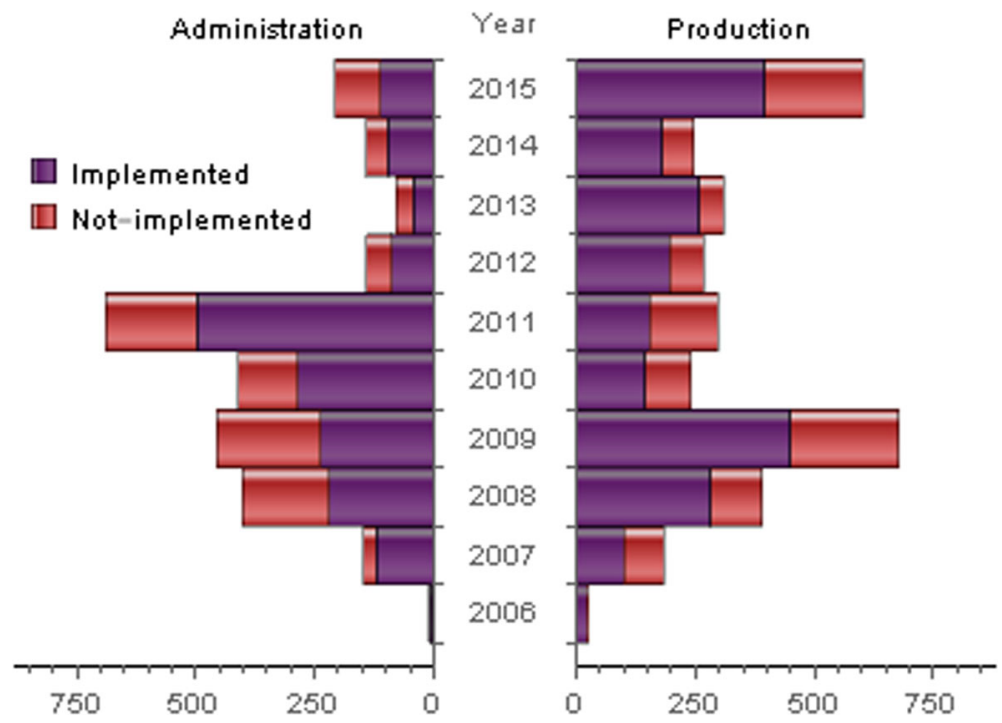

Fig. 2 The number of implemented and non-implemented employee suggestions per departments of company $\mathrm{X}$ broken down into years 
an idea and its implementation is faster. The initial years of the system operation witness improvements to a large number of irregularities. After 2012, the number of suggestions slightly dropped. Whereas, in the production department, proposals for change result from experiences, a repetitive process which takes much longer than in the management area. Additionally, the company manufactures large appliances and despite the fact that there is a serial production, it is not done on such scale as in the automotive industry which may result in prolongation the evaluation and generation of new ideas.

\section{Conclusion}

Significantly, it should be noticed that production and administration departments differ in terms of the number of employee suggestions. It is a very interesting outcome in the field of research on functioning of employee suggestions systems. In their research, Lasardo, et al. enumerate a lot of factors influencing success of an employee suggestion system, such as competition, an award system, satisfaction, communication, support, organizational obstacles, an implementation manner and others [24], however they do not mention importance of an operation area as a parameter. Attention should be drawn to the fact that certain elements such as implementation of the system may depend on a department of a company. For instance, a sub-process of evaluating a new solution in the production will be much more complicated than in the administration - more people are involved, more time for evaluation is needed, more difficult verification of possible implementation of a solution.

The elaboration also continues the research of the company, as it evaluates [15], effectiveness of a production department whereas [26] analysed types of waste in the enterprise. The elaboration analysed dependency between departments, the type (classes) of problems occurring in work organization - it has turned out that the type of department does not affect the amount of "muda" in particular areas which is especially interesting in the context of the research, Despite a similar amount of waste in particular department the number of employee suggestions is different.

The analysis made resulted in the conclusions as follows:

- the nature of an enterprise - an organization department (area of operations) is a significant parameter among parameters influencing an employee suggestion system. The literature does not consider this aspect.

- within a company and its various departments - despite occurrence of the classes of waste and the manner of implementation - effectiveness, an operation manner of an employee suggestion system may significantly differ.

A very important question that arises is the reason for the observed differences. We hypothesize that in enterprises researched by Lasardo and co-workers there was a different percentage share of projects relative to repetitive processes. In the discussed enterprise $\mathrm{X}$ a large number of projects resulted from the area of the company's activity. Let us pay attention (Table 1) to a certain tendency. In the company, when a new employee suggestion system appears, the quantity increases significantly to a certain maximum number, which in company X occurred in 2009, when 1133 employee suggestions were submitted. Then the quantity began to decrease and stabilized at a certain level. Let us see, however, that in the case of the administration department from 2012, the number of employee suggestions ranges from 80 to 208 . While in the case of production, where the impact of projects 
is important, the range is much higher $(357=604-246)$. Therefore, it seems logical that employee systems operating in lean manufacturing significantly differ in the indicated context from those in lean remanufacturing.

It should be noted that most lean remanufacturing research does not formally mention the ESS. Kurilova-Palisaitiene et al. [19] presents the challenges facing remanufacturing. It also indicates ways to improve the company's operations based on lean. ESS does not appear among the so called lean-based improvement. The closest group is organizing employee cross-training and learning through problem solving. The definition includes "exchange experience" and "gain knowledge", but without specifying how such goals will be achieved. This can be done using the ESS.

The differences in the functioning of the ESS in Lean management and lean remanufacturing are based only on the conclusions of the article. There are no other studies in this area in the literature. In Lean management, companies most often deal with a repeatable process, while in lean remanufacturing with original projects. Due to the characteristics of the projects, employees should be taught how to handle them all the time. Therefore, in the case of lean remanufacturing, there are more employee suggestions in the production area, while the management area remains unchanged. In the context of lean remanufacturing, we must educate employees about the specifics of the project each time, so more substantive training is needed, and in lean management, reminding training is sufficient.

The authors realise that their elaboration does not exhaust the subject of dependency of employee suggestion system's operation considering the criterion of company departments. The subject is particularly interesting and requires in-depth analyses accounting for theoretical and practical aspects.

Open Access This article is licensed under a Creative Commons Attribution 4.0 International License, which permits use, sharing, adaptation, distribution and reproduction in any medium or format, as long as you give appropriate credit to the original author(s) and the source, provide a link to the Creative Commons licence, and indicate if changes were made. The images or other third party material in this article are included in the article's Creative Commons licence, unless indicated otherwise in a credit line to the material. If material is not included in the article's Creative Commons licence and your intended use is not permitted by statutory regulation or exceeds the permitted use, you will need to obtain permission directly from the copyright holder. To view a copy of this licence, visit http://creativecommonshorg/licenses/by/4.0/.

\section{References}

1. Adejo M (2020) Difference between development and underdevelopment in economy of countries source: www.legit.ng/1215170-difference-development-underdevelopment-economy-countries.html

2. Amezquita T, Bras B (1996) Lean remanufacture of an automobile clutch. In: Proceedings of First International Working Seminar on Reuse, Eindhoven, The Netherlands, p 6

3. Arif M, Aburas HM, Kuwaiti AA, Kulonda D (2010) Suggestion systems: a usability-based evaluation methodology. JKAU Eng. Sci. 21(2):61-79

4. Black J (1999) Kaizen (continuous improvement) for small- and medium-sized companies. CIRAS News 33(2)

5. Brdulak A (2014) The importance of sustainable development - the ecological aspect, Zeszyty Naukowe wyższej szkoły Bankowej we wrocławiu, No. 1 (39). In: Challenges and conceptions in contemporary logistics, pp 223-234

6. Carvalho H, Duarte S, Machado VC (2011) Lean, agile, resilient and green: divergencies and synergies. Int J Lean Six Sigma 2(2):151-179

7. Charles AA, Chucks OK (2012) Adopting the kaizen suggestion system in South African lean automotive components companies. Sci J Bus Manag, vol 2012

8. Daly J (2015) Lean remanufacturing. Reman Industry Focus (RIF), source:, www.duxes.cn/eNewsletter/ RIF16/en/articles_3/ 
9. Du Plessis AJ, Marx A, Wilson G (2008) Generating ideas and managing suggestion systems in organisations: some empirical evidence. Int. J. Knowl. Cult. Chang. Manag 8(4):133-140

10. Fargher JSW (2003) Lean: dealing with eight wastes. ReMaTec News 24-25

11. Gołaś H, Mazur A, Gruszka J, Szafer P (2016) Application of the suggestion system in the improvement of the production process and product quality control, vol 145, p 062005

12. Göransson D, Tunovic A (2012) Process improvement in an office environment using Lean Six Sigma, Finding ways to work smarter instead of harder in day-to-day customer service operations, Diploma work No. 100/2012 at the Department of Materials and Manufacturing Technology, Chalmers university of technology, Gothenburg, Sweden

13. Imai M (1986) Kaizen: the key to japan's competitive success, 1st edn. McGraw-Hill Education, New York

14. Jabeen F, Mehmood K., Mehrajunnisa M (2020) Strategic drivers to promote employee suggestion schemes in GCC organizations. Evidence-based HRM 8(3)

15. Jagodziński J, Ostrowski D (2016) Optymalizacja wybranego procesu produkcyjnego w oparciu o zasade ciagłego doskonalenia na przykładzie przedsiebiorstwa X, Zeszyty Naukowe Politechniki Czestochowskiej. Zarz,adzanie nr 24, t. 2. 201-214

16. Jakubik M, Kagan R, Hanusyk K, Koch T (2013) Motywowanie pracowników w środowisku Lean. In: XIII international lean management conference, Wrockław

17. Kanikuła T, Koch T (2010) Methodology of designing disassembly and reassembly processes using lean thinking approach. In: IFIP International federation for information processing 2010 APMS 2009, vol 338, pp 11-18. IFIP AICT

18. Kurilova-Palisaitiene J, Sundin E (2014) Challenges and opportunities of lean remanufacturing. Int J Autom Technol 8(5)

19. Kurilova-Palisaitiene J, Sundin E, Poksinska B (2018) Remanufacturing challenges and possible lean improvements. J Clean Prod 172

20. Liker J, Meier D (2005) The toyota way fieldbook: a practical guide for implementing toyota's 4Ps paperback

21. Lisiecka K, Burka I (2015) ŹRódła powstawania marnotrawstwa w organizacjach na przykładzie usługowych przedsiebiorstw ciepłowniczych, Zeszyty Naukowe Uniwersytetu Ekonomicznego w Katowicach. No. 233 Zarzadzanie 3

22. Miller J, Wroblewski M, Villafuerte J (2014) Kultura Kazien — Budowanie i utrzymanie kultury ciagłego doskonalenia MT Biznes

23. Naser DS, Fadavi MS (2015) Enrichment of employees' suggestion system. Eur J Bus Soc Sci 4(06):112

24. Lasrado F, Arif M, Rizvi A (2014) Employee suggestion system assessment model: the best practice scenarios. J Strat Human Res Manag 3(2)

25. Lasrado F, Gomiscek B (2015) A tool to measure maturity of an employee suggestion scheme. Manag Prod Eng Rev 6(2):4-13

26. Ostrowski D, Jagodziński J (2017) Analiza zależności typów marnotrawstw identyfikowanych w działach administracyjnych na przykładzie przedsiebiorstwa transportowego, przedsiebiorczość i zarzadzanie, Zeszyty Naukowe, tom XVIII, zeszyt 8 cześć I, Wydawnictwo Społecznej Akademii Nauk Łódź - Warszawa

27. Pakdel A, Wahab SRA, Lotfi M (2014) Differences between traditional systems and modern suggestion system. Am J Bus Econ Manag 2014 2(2):64-69

28. Pawlik E, Ijomah W, Corney J (2013) Current state and future perspective research on lean remanufacturing - focusing on the automotive industry. In: Advances in production management systems. competitive manufacturing for innovative products and services. Springer, Berlin, pp 429-436

29. Pawlik E, Ijomah W, Corney J (2016) Lean remanufacturing. In: The Routledge companion to lean management. Routledge

30. Biznesu P (2017) Tam, gdzie rytm pracy wyznacza Kaizen i Jidoka - dodatek tematyczny do Pulsu Biznesu z dnia 20.11.2017, s 2

31. Recht R, Wilderom C (1998) Kaizen and culture: on the transferability of Japanese suggestion systems. Int Bus Rev 7(1)

32. Shimokawa K, Fujimoto T (2009) The birth of lean. In: Conversation with Taiichi Ohno, eiji Toyoda, and other figures who shaped Toyota Managment, Cambridge

33. Wilson M (2012) Understanding The Kaizen Philosophy, Kaizen News, December 25, https://www. kaizen-news.com/understanding-the-kaizen-philosophy/ 
34. Yadav G, Desai TN (2016) Lean Six sigma: a categorized review of the literature. Int. J. Lean Six Sigma 7(1):2-24

35. Yadav G, Luthra S, Huisingh D, KumarMangla SK, Eknathnarkhede BE, Liu Y (2019) Development of a lean manufacturing framework to enhance its adoption within manufacturing companies in developing economies. J Clean Prod

Publisher's note Springer Nature remains neutral with regard to jurisdictional claims in published maps and institutional affiliations. 